
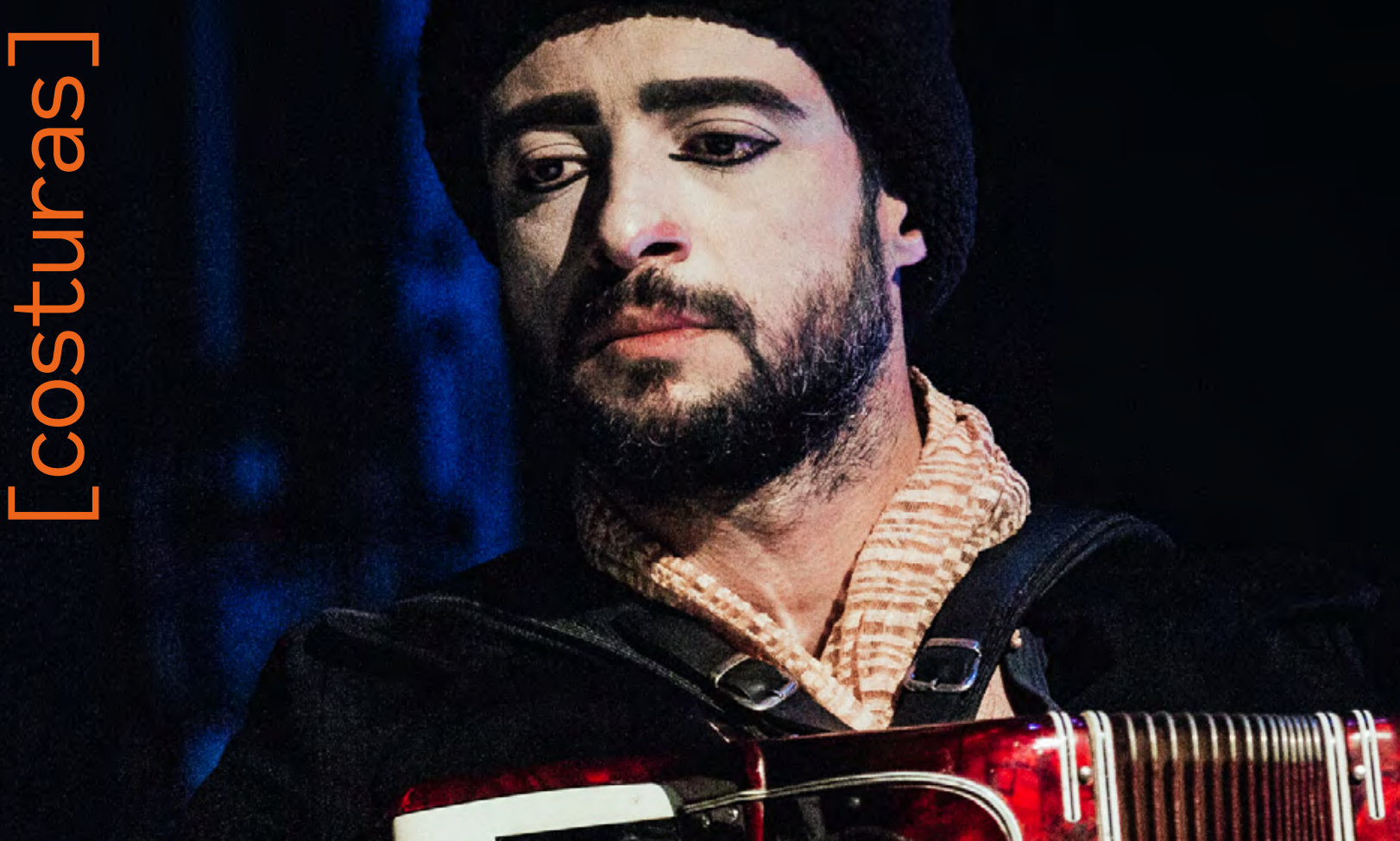


\section{Sobre conhecer Pam Tait, figurinista, em Surrey, Reino Unido}

On how I met costume designer Pam Tait in Surrey, United Kingdom 


\section{FAUSTO VIANA ${ }^{1}$}

ORCID: https://orcid.org/0000-0002-4823-3626

Em 2018, aconteceu o encontro Critical Costume, em Surrey, na Inglaterra. 0 evento foi apoiado pela Universidade de Surrey e teve a organização planejada pela professora da casa Rachel Hann e por Sofia Pantouvaki, professora na Finlândia. Eu era membro do comitê diretivo, junto com Katie Barford (UK), Donatella Barbieri, University of the Arts London (UK), Sidsel Bech, Edge Hill University (UK), Jessica Bugg, RMIT (AU), Sarah Gilligan, Hartlepool College (UK), Christina Lindgren, Oslo National Academy of the Arts (NO), Deborah Nadoolman Landis, UCLA (US), Aoife Monks, Queen Mary University of London (UK), Simona Rybáková, Chair of the OISTAT Performance Design Commission / Costume (CZ); Natalie Rewa, Queens University at Kingston (CA), Marlis Schweitzer, York University (CA) e Sodja Zupanc Lotker, Academy of Performing Arts in Prague (CZ).

Eram muitos encontros, discussões e exposições. Entre as melhores coisas que acontecem em eventos deste tipo estão a troca de informações, os questionamentos, a mediação de mesas, apresentação de trabalhos e... conhecer pessoas.

Foi lá que conheci Pam Tait, que de longe me parecia uma destas pessoas encantadoras que a gente tem que conhecer. Eu a vi conversando no almoço, peguei o meu kit refeição e fui sentar ao lado dela, em uma destas poltronas de saguão. A conversa era muito interessante e logo se dirigiu para a vida pessoal de cada um. Pam é uma figurinista bastante ativa, e professora também, e contou ali, naturalmente, parte da história que o leitor vai encontrar aqui na sequência, sobre seu relacionamento com o marido, que teve um final de vida trágico.

Pam era, infelizmente, uma sobrevivente de uma vida plena de agressões físicas e emocionais. Meu interesse primeiro, depois de saber como ela tinha sobrevivido, foi entender como o processo criativo dela se manteve íntegro ao longo de tantos anos, como ela poderia ter criado - e criado coisas belíssimas! - dentro de um ambiente tão conflituoso como o em que estivera.

Naquele mesmo momento, perguntei se ela não gostaria de escrever para o nosso dossiê, tratando do tema guerra interna, guerrilha pessoal, contando sua experiência. Ela topou imediatamente e expliquei brevemente como deveria ser para a publicação que estávamos pensando.

Naturalmente, o processo não foi tão simples assim.

Nesta nova etapa de vida, Pam viaja bastante para todos os lados na Inglaterra e vive ocupada. Achei curioso deixar para o leitor pistas do que significa trabalhar com uma pessoa tão pulsante. Pedi a ela um currículo, para poder escrever mais sobre os trabalhos que ela fez, em uma apresentação formal do trabalho dela. Esperei dias, e nada de resposta. Escrevi novamente e recebi a seguinte mensagem: "Já está no seu Messenger"!

\footnotetext{
${ }^{1}$ Doutor em teatro e museologia. Professor de cenografia e indumentária, Escola de Comunicações e Artes, Universidade de São Paulo, Brasil.

E-mail: faustoviana@uol.com.br. Lattes: http://lattes.cnpq.br/8433918896586792.
} 
Como pude não notar? Averiguando melhor, foi este o currículo que ela me enviou, neste formato:

FIGURA 1- MENSAGEM RECEBIDA PELO APLICATIVO MESSENGER.

ENVIADA DE PAM TAIT PARA FAUSTO VIANA. A GRAFIA FOI MANTIDA COMO RECEBIDA.

$\mathrm{CV}$

BA English st Hilda's Oxford Work with royal court 80/83- designed premiere of top girls 85 asst costume designer on Sid and Nancy Work in tv and film to 2000 inc. on a land of plenty and queer as folk 2000-2011 work at dept of drama university of Bristol 2011-2016 teaching fellow uni of Bristol 2016 to present - work with impermanence dance, house of strays , Jeremy Dellers 'we're here because we're here', film- ballet of the nations Currently designing set and costume for Brechts Baal opening at Bristol old vic

FONTE: TAIT, Pam. [CV]. Destinatário: Fausto Viana. 18 mar. 2019. 1 mensagem de aplicativo Messenger.

E só.

Pedi uma imagem dela para ilustrar o artigo, apresentando-a para o público leitor. Eis a que ela me enviou, com a seguinte mensagem:

FIGURA 2 - A FIGURINISTA PAM TAIT, PROVAVELMENTE EM UMA SELFIE

Not so great but all I have! X

Sent from my iPhone

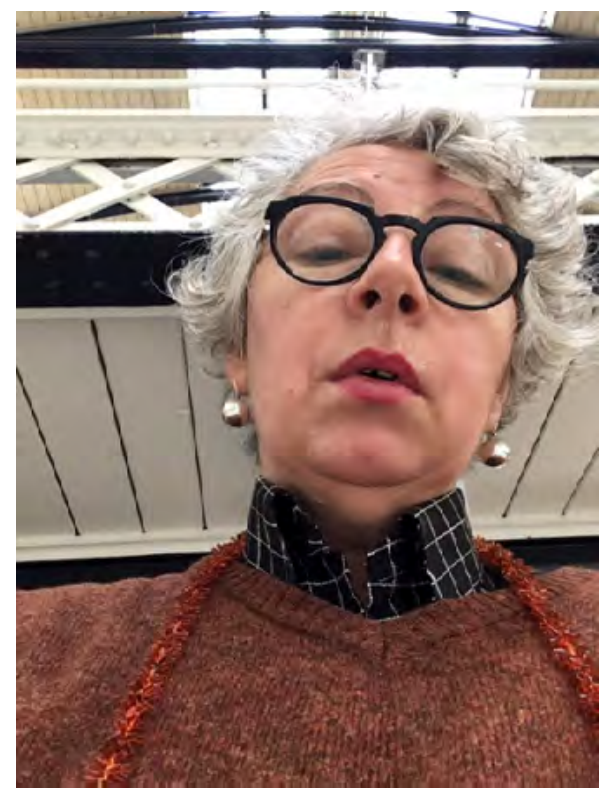

FONTE: TAIT, Pam. Selfie. 7 jul. 2018. Fotografia enviada por aplicativo Messenger. 
Eu ri muito, naturalmente, porque a foto diz muito do espírito de Tait, algo como: "espera, se eu tenho que resolver, deixa que eu dou um jeito já!". Tira a foto e manda. Mas tive que ficar insistindo até que, ao menos dos espetáculos, ela me mandasse algo publicável.

Não foi um grande sucesso também, mas era o que eu tinha para ao menos mostrar ao leitor que trabalho interessante esta senhora fazia (ver figuras 4 e 5).

FIGURA 3 - RESPECTIVAMENTE, FIGURINOS DE PAM TAIT PARA PRODUÇÕES DO BRISTOL UNIVERSITY DEPARTMENT OF DRAMA EM 2011, 2012 E 2013
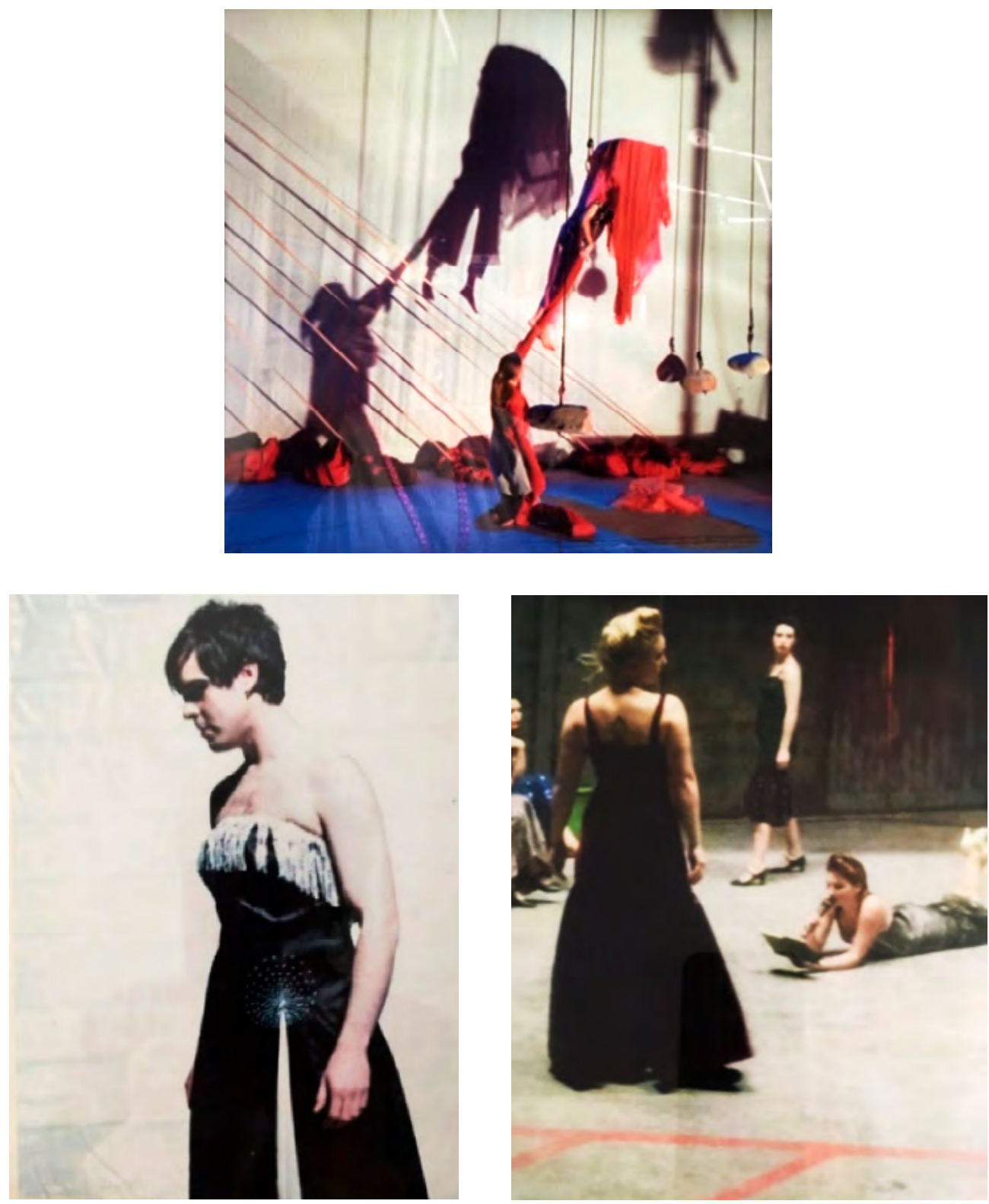

FONTE: acervo Pam Tait. 
FIGURA 4 - RESPECTIVAMENTE, FIGURINOS DE PAM TAIT PARA UMA PRODUÇÃO DE 2015 DO BRISTOL UNIVERSITY DEPARTMENT OF DRAMA E PARA O ESPETÁCULO DE DANÇA EGON SCHIELE, EM 2019
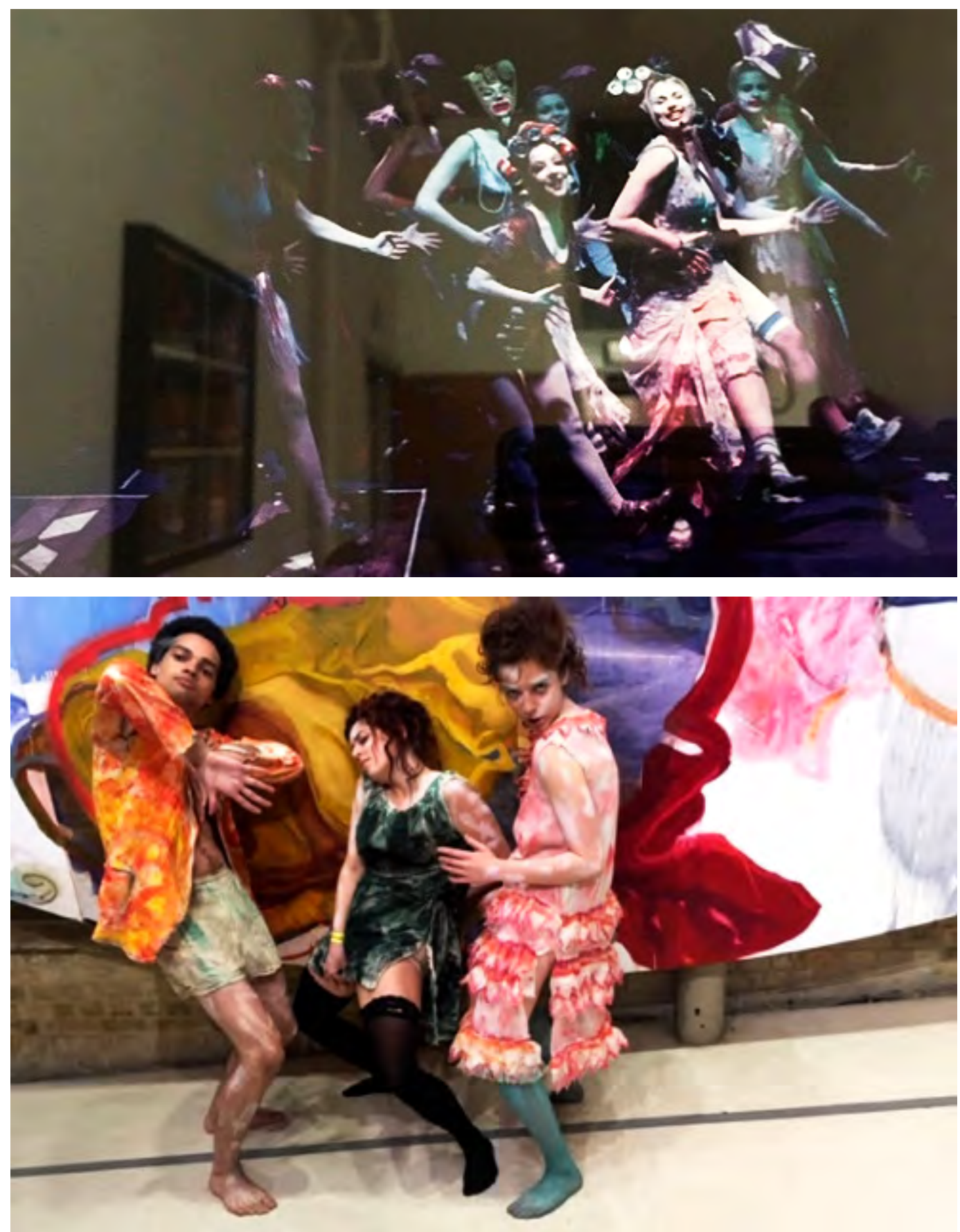

FONTE: acervo Pam Tait.

Termino assim esta breve introdução ao trabalho de Pam Tait, e que seu relato seja uma inspiração para nós todos. E que a vida da Pam tenha, agora, a merecida paz, como ela pede no final de seu texto. 